\section{Ultrasonographic quantification of pleural effusion: comparison of four formulae}

\author{
Bolanle Olubunmi Ibitoye', Bukunmi Michael Idowu', Akinwumi Babatunde Ogunrombi², \\ Babalola Ishmael Afolabi'
}

Departments of ${ }^{1}$ Radiology and ${ }^{2}$ Surgery, Obafemi Awolowo University Teaching Hospitals Complex, Ile-Ife, Nigeria

Purpose: The purpose of this study was to evaluate the correlations of ultrasonographically estimated volumes of pleural fluid with the actual effusion volume in order to determine the most reliable formula.

Methods: In 32 consecutive patients with clinically diagnosed pleural effusion, an ultrasound estimation was made of the volume of effusion using four different formulae, including two in the erect position and two in the supine position. Closed-tube thoracostomy drainage using a 28-Fr chest tube was performed. The total drainage was calculated after confirmation of full lung re-expansion and complete drainage by plain chest radiographs and ultrasound. The ultrasonographically estimated volume was compared to the actual total volume drained as the gold standard.

Results: There were 14 female and 18 male subjects. The mean age of all subjects was $41.56 \pm 18.34$ years. Fifty percent of the effusions were in the left hemithorax. Metastatic disease accounted for the plurality of effusions (31.2\%). The mean total volume drained for all the subjects was $2,770 \pm 1,841 \mathrm{~mL}$. The ultrasonographically estimated volumes for the erect 1, erect 2 , supine 1 , and supine 2 formulae were $1,816 \pm 753 \mathrm{~mL}, 1,520 \pm 690 \mathrm{~mL}, 2,491 \pm 1,855 \mathrm{~mL}$, and $1,393 \pm 787 \mathrm{~mL}$, respectively. The Pearson correlation coefficients $(r)$ for the estimate of each formula were $0.75,0.81,0.62$, and 0.63 , respectively.

Conclusion: Although both erect formulae showed similar correlations, the erect 2 formula (Goecke 2) was most closely correlated with the actual volume drained.

Keywords: Pleural effusion; Ultrasonography; Quantification; Volumetry; Thoracentesis; Volume estimation

\section{Introduction}

Pleural effusion is an excessive accumulation of fluid in the pleural space resulting from excess fluid production, decreased absorption, or both [1]. Approximately 1-10 $\mathrm{mL}$ of fluid is normally present in the pleural space [1-5], maintained by the balance between the hydrostatic and oncotic forces in the visceral and parietal pleural vessels and extensive lymphatic drainage $[1,2]$. Pleural effusion results when this equilibrium is disrupted. The daily production of pleural fluid is about $10 \mathrm{~mL}$ [3] or $0.01-$

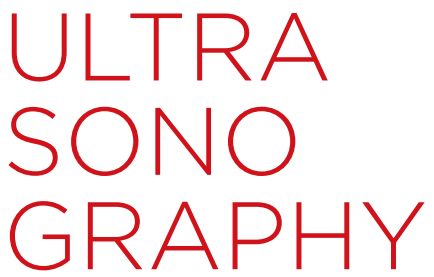

\section{ORIGINAL ARTICLE}

https://doi.org/10.14366/usg. 17050 pISSN: 2288-5919 • elSSN: 2288-5943 Ultrasonography 2018;37:254-260

Received: July 8, 2017

Revised: October 18, 2017

Accepted: October 18, 2017

Correspondence to:

Bukunmi Michael Idowu, MBBS,

FWACS, FMCR, Department of Radiology, Obafemi Awolowo University Teaching Hospitals Complex PMB 5538, lle-Ife, Osun State, Nigeria

Tel. +234-8032164229

E-mail: ibmcontacts@gmail.com

This is an Open Access article distributed under the terms of the Creative Commons Attribution NonCommercial License (http://creativecommons.org/ licenses/by-nc/3.0/) which permits unrestricted noncommercial use, distribution, and reproduction in any medium, provided the original work is properly cited.

Copyright (C) 2018 Korean Society of Ultrasound in Medicine (KSUM)

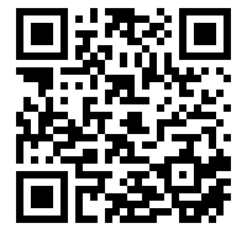

How to cite this article:

Ibitoye BO, Idowu BM, Ogunrombi AB, Afolabi $B I$. Ultrasonographic quantification of pleural effusion: comparison of four formulae. Ultrasonography. 2018 Jul;37(3):254-260. 
$0.02 \mathrm{~mL} / \mathrm{kg} / \mathrm{hr}$ [6], which is absorbed continuously, such that the remaining pleural fluid is about $0.1-0.2 \mathrm{~mL}$ per kilogram of body weight [6].

Ultrasonographically, pleural effusion volume can be estimated quantitatively or qualitatively. Qualitative estimations classify effusion as minimal, moderate, or massive [7,8], while a quantitative approach involves the use of various formulae [9-12].

Compared to radiography, ultrasonography has the advantage of being non-invasive, cost-effective, readily available, and repeatable. It is also radiation-free. Furthermore, chest ultrasonography shows better sensitivity and reliability than radiography $[9,13]$. While a minimum of $150 \mathrm{~mL}$ is required to detect effusion by radiography in the erect position [14], effusions as small as $5 \mathrm{~mL}$ can be detected ultrasonographically with $100 \%$ sensitivity $[4,15]$.

Pleural effusion is frequently managed by thoracocentesis. Sometimes, the actual amount of effusion is at variance with the clinical presentation, and it is doubtful whether to drain. The ideal ultrasonographic formula for pleural effusion volume estimation should be simple, accurate, and rapidly/easily performed. This study was carried out to compare four quantitative ultrasonographic formulae to determine which best predicted the actual volume. Our results should be helpful in clinical decision-making regarding which patients require chest intubation and in assessing the completeness of effusion drainage before extubation.

\section{Materials and Methods}

This was a prospective cross-sectional study. In 32 consecutive

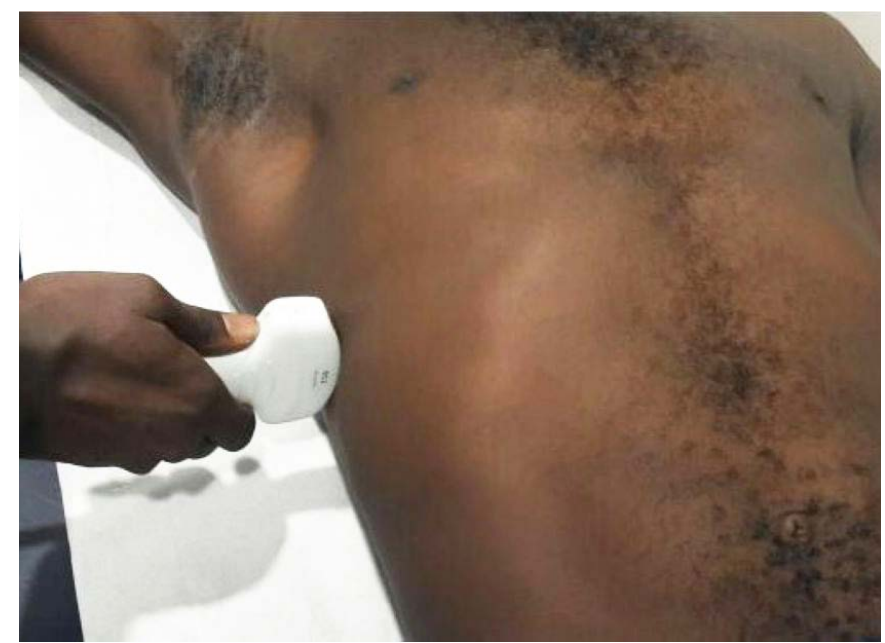

A

Fig. 1. Right-sided pleural effusion in a 35-year-old man.

A. This image shows the patient and probe positions for obtaining measurements for the supine 1 and 2 formulae. B. The resultant chest ultrasonography shows the maximum perpendicular distance between the pulmonary surface and the chest wall at maximal inspiration (cursors).

e-ultrasonography.org

Ultrasonography 37(3), July 2018 patients with a clinical and radiologic diagnosis of pleural effusion, an estimation of the pleural effusion volume was made using a Mindray real-time ultrasound machine model DC-6 or DC-7 (Shenzhen Mindray Biomedical Electronics, Shenzhen, China) with a convex transducer (frequency of 3.8-5.0 MHz). Four different sonographic formulae were used for volume estimation.

Patients aged between 10 and 80 years, with a clinical and radiological diagnosis of effusion $(>10 \mathrm{~mm}$ of pleural separation by fluid on ultrasonography, with the fluid layer changing with respiration and with different body positions $[8,11,12,16])$, and who were well enough to obey the instructions given, particularly regarding breath control, were included in this study. None of the subjects was on mechanical ventilation.

A total of 52 subjects were recruited initially but 20 subjects were excluded. The exclusion criteria were loculated/encysted effusions, empyema, and patients at the extreme points of life who could not sit erect and/or obey breathing instructions. Those with thoracic deformities, diaphragmatic pathology, previous chest surgery, and incomplete fluid drainage on post-intubation ultrasonography $(>5$ $\mathrm{mm}$ of separation of the pleural layers) [16] were excluded. Patients with empyema or atelectasis without effusion on the preliminary sonographic evaluation were also excluded from the study. Ethical clearance was granted by the hospital's Ethics and Research Committee. Informed consent was obtained from all participants.

The ultrasonographic examination was first done with the patient flatly supine (no pillow or head rest) to obtain values (in millimeters) for the supine formulae. The chest was insonated at the laterodorsal/ posterolateral part of the chest wall through the intercostal spaces

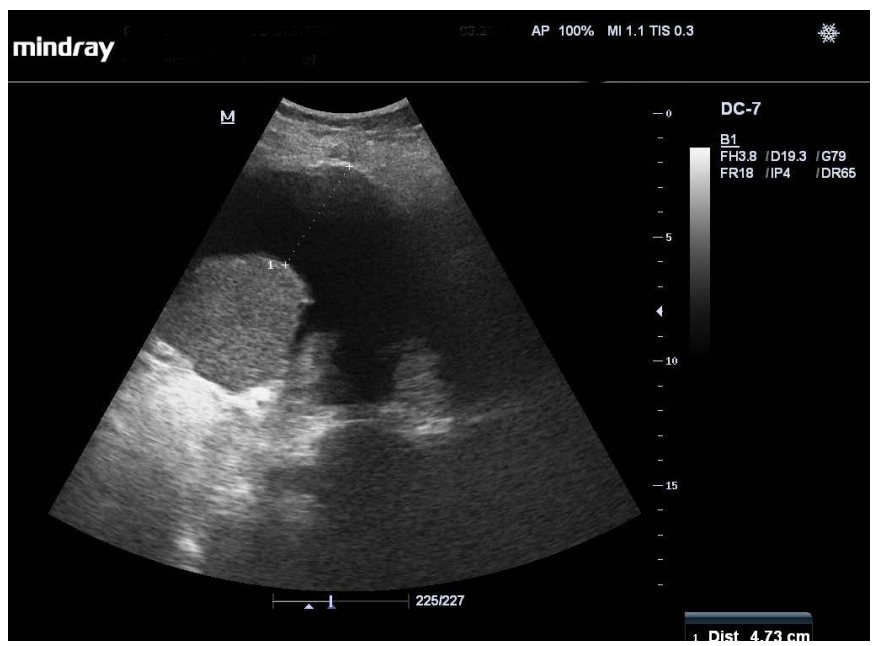

B 
(as an acoustic window), with the transducer perpendicular to the chest wall (transverse scan with no angling or tilting of the transducer) [9]. Measurements were taken at maximum inspiration, with the patients holding their breath. The maximum perpendicular (interpleural) distance between the posterior surface of the lung (visceral pleura) and the posterior chest wall (parietal pleura) was obtained [9], as shown in Fig. 1A and B. Transducer angulation or tilting was strictly avoided to forestall scanning obliquely to the transverse plane with the attendant risk of overestimating the effusion width [11].

Thereafter, patients sat in a fully erect position (no slouching or reclining), and measurements (in centimeters) were taken for the erect formulae. The dorsolateral/posterolateral aspect of the chest wall was insonated through the intercostal spaces with the

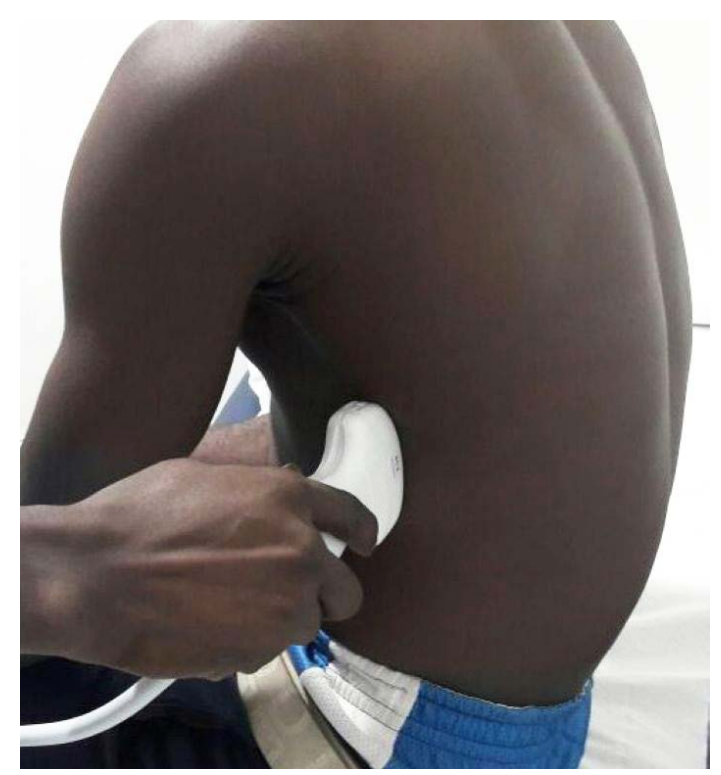

A

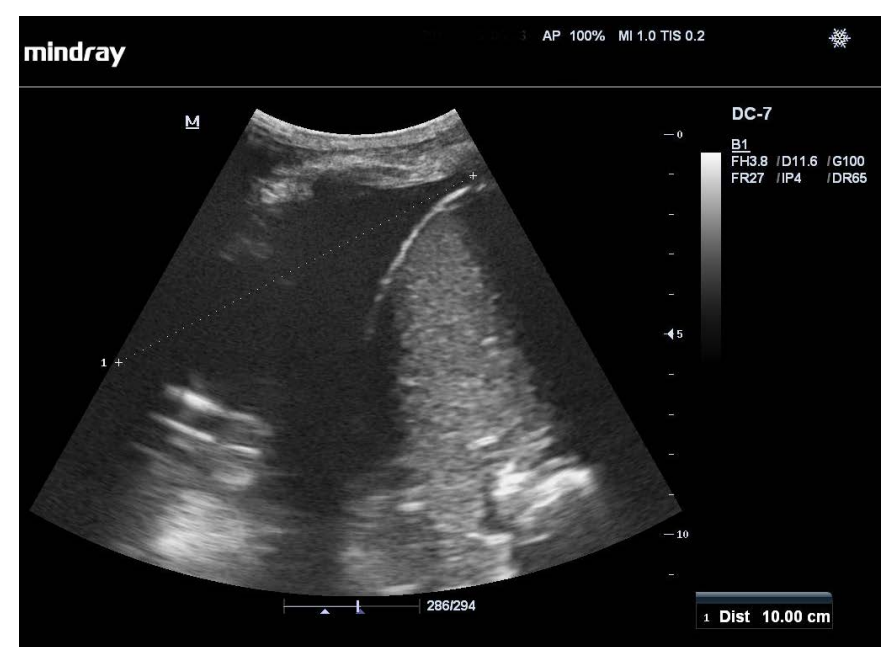

B transducer oriented longitudinally along the long axis of the chest (Fig. 2A-C). The craniocaudal extent (lateral height) of the effusion and the lung base-to-diaphragm distance were measured at endexpiration [10]. Each measurement was repeated 3 times and the average value was recorded for the statistical analysis. The effusion volume estimates were subsequently calculated from the different formulae as follows:

\section{Erect 1 (Goecke 1): $E V=X \times 90$,}

where $\mathrm{EV}=$ =estimated effusion volume $(\mathrm{mL}) ; \mathrm{X}=$ craniocaudal extent $(\mathrm{cm})$ of the effusion at the dorsolateral chest wall measured in erect/ sitting position with the probe oriented longitudinally; $90=$ empirical factor/constant [10].

Fig. 2. Right-sided pleural effusion in a 60-year-old man. A. This image depicts the patient and probe positions for obtaining measurements for the erect formulae. B, C. Corresponding chest sonography shows the craniocaudal extent (cursors) of the effusion (B) at the dorsolateral chest wall (erect 1 formula), as well as the lung base to mid-diaphragm distance/subpulmonary height (C) of the effusion (erect 2 formula).

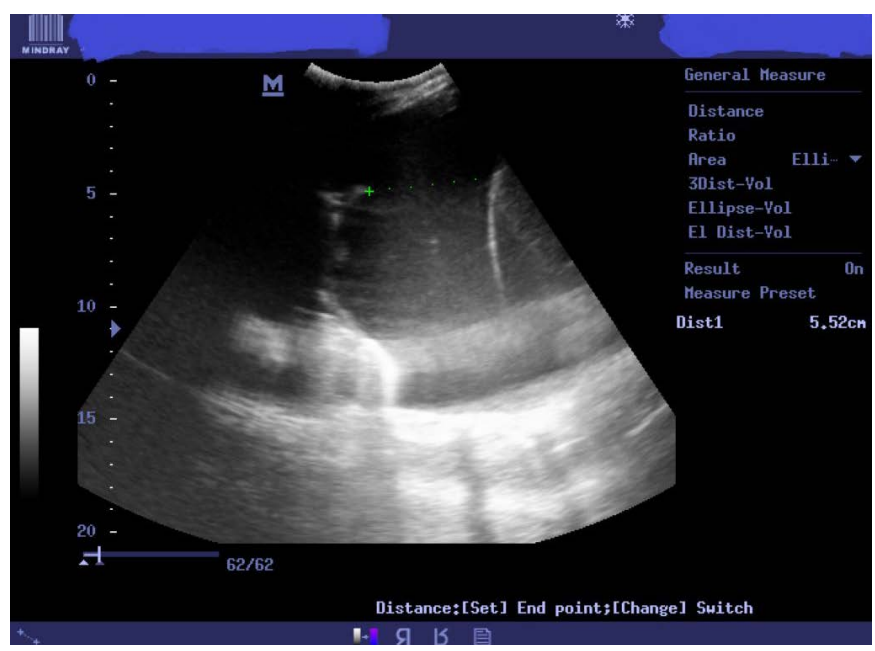

C 
Erect 2 (Goecke 2): $\mathrm{EV}=(\mathrm{X}+\mathrm{LDD}) \times 70$,

where $E V=$ estimated effusion volume $(\mathrm{mL}) ; \mathrm{X}=$ craniocaudal extent of the effusion at the dorsolateral chest wall measured in the erect/sitting position with the probe oriented longitudinally; $\mathrm{LDD}=$ lung base to mid-diaphragm distance/subpulmonary height of the effusion (cm); 70=empirical factor/constant [10].

\section{Supine 1 (Eibenberger): $\mathrm{EV}=47.6 \mathrm{X}-837$,}

where $E V=$ estimated effusion volume $(\mathrm{mL}) ; \mathrm{X}=$ maximum perpendicular distance between the pulmonary surface and the chest wall at maximal inspiration $(\mathrm{mm})$ with the probe in the transverse position, perpendicular to the chest wall [9].

\section{Supine 2 (Balik): $\mathrm{EV}=20 \mathrm{X}$}

where $\mathrm{EV}=$ estimated effusion volume $(\mathrm{mL}) ; \mathrm{X}=$ maximum perpendicular distance between the pulmonary surface and chest wall at maximal inspiration $(\mathrm{mm})$ with the probe in transverse position, perpendicular to the chest wall $[11,12]$.

Thoracocentesis was then performed under ultrasound guidance. A 28-Fr chest tube (Tyco Healthcare Kendall, Argyle, NY, USA) was inserted in the mid-axillary line through the fifth intercostal space and connected to an underwater seal drainage. Complete lung expansion on radiography and $<5 \mathrm{~mm}$ separation of the pleural layers on ultrasonography were taken as evidence of total drainage of the effusion. The drained volume was then recorded as the total effusion volume.

The data were analyzed using SPSS ver. 20 for Windows (IBM Corp., Armonk, NY, USA). Pearson correlation analysis was performed to determine the extent of correlation between ultrasonographically estimated effusion volumes and the actual volume drained.

The study population was further subdivided based on age into two categories: $>20$ years old and $<20$ years old [17-19].

The degrees of correlation were classified as follows: $r=0-0.20$, very low and probably meaningless correlation; $r=0.21-0.40$, low correlation that might warrant further investigation; $r=0.41-0.60$, reasonable correlation; $r=0.61-0.80$, high correlation; and $r=0.81$ -1.0 , excellent/very high correlation [20]. The level of statistical significance was set at $\mathrm{P} \leq 0.05$.

\section{Results}

A total of 32 patients were analyzed in this study. They were aged $10-80$ years, with a mean age of $42 \pm 18$ years. There were 14 females $(43.8 \%)$ and 18 males $(56.3 \%)$. Half of the effusions were right-sided and the other half were on the left; there were no bilateral effusions.

The etiological causes of the pleural effusion are shown in Table 1. Chest malignancies accounted for the plurality of effusions. Pulmonary tuberculosis was the second most common etiological cause of effusion. Eighteen patients had a benign etiology, 11 had effusion that was malignant in origin, and three cases were of unknown etiology.

The mean total volume of actual pleural fluid drained for all the subjects was $2,770 \pm 1,841 \mathrm{~mL}$. The ultrasonographically estimated mean effusion volumes obtained using the various formulae are displayed in Table 2.

When all the subjects were analyzed together (uncategorized), the erect 2 (Goecke 2) formula showed the strongest (excellent/ very high) correlation with the actual volume drained $(r=0.81$, $\mathrm{P}<0.001$ ) followed by the erect 1 (Goecke 1) formula, which had a

Table 1. Etiologies of pleural effusion in the subjects

\begin{tabular}{lc}
\hline \multicolumn{1}{c}{ Etiology } & No. (\%) \\
\hline Pulmonary tuberculosis & $9(28.1)$ \\
Community-acquired pneumonia & $5(15.6)$ \\
Malignancy (including metastases) & $11(34.4)$ \\
Hemothorax & $2(6.3)$ \\
Chronic renal failure (with heart failure) & $1(3.1)$ \\
Corrosive esophagitis & $1(3.1)$ \\
Unknown & $3(9.4)$ \\
\hline
\end{tabular}

Table 2. Actual volume drained and corresponding ultrasonographic estimates in various subsets of participants

\begin{tabular}{lclllc}
\hline \multicolumn{1}{c}{ Category } & Volume drained $(\mathrm{mL})$ & Erect $1(\mathrm{~mL})$ & Erect $2(\mathrm{~mL})$ & Supine $1(\mathrm{~mL})$ & Supine $2(\mathrm{~mL})$ \\
\hline All subjects $(\mathrm{n}=32)$ & $2,769 \pm 1,841$ & $1,816 \pm 753$ & $1,520 \pm 690$ & $2,491 \pm 1,855$ & $1,393 \pm 787$ \\
Right-sided effusion $(\mathrm{n}=16)$ & $3,215 \pm 2,019$ & $1,955 \pm 710$ & $1,756 \pm 731$ & $2,739 \pm 2,113$ & $1,491 \pm 903$ \\
Left-sided effusion $(\mathrm{n}=16)$ & $2,324 \pm 1,584$ & $1,677 \pm 1,677$ & $1,358 \pm 1,358$ & $2,242 \pm 2,242$ & $1,294 \pm 1,294$ \\
Age $<20$ yr $(\mathrm{n}=5)$ & $1,327 \pm 900$ & $1,037 \pm 556$ & $1,027 \pm 467$ & $1,046 \pm 979$ & $792 \pm 412$ \\
Age $>20$ yr $(\mathrm{n}=27)$ & $3,037 \pm 1,855$ & $1,960 \pm 700$ & $1,631 \pm 692$ & $2,758 \pm 1,865$ & $1,504 \pm 794$ \\
\hline
\end{tabular}

Values are presented as mean \pm SD. 
Table 3. Correlation between sonographic estimates and actual drainage volume in various subsets of participants

\begin{tabular}{|c|c|c|c|c|c|c|c|c|}
\hline \multirow{2}{*}{ Parameter } & \multicolumn{2}{|c|}{ Erect 1} & \multicolumn{2}{|c|}{ Erect 2} & \multicolumn{2}{|c|}{ Supine 1} & \multicolumn{2}{|c|}{ Supine 2} \\
\hline & r-value & P-value & r-value & P-value & r-value & P-value & r-value & P-value \\
\hline All subjects & 0.75 & 0.001 & 0.81 & 0.000 & 0.62 & 0.000 & 0.63 & 0.000 \\
\hline \multicolumn{9}{|l|}{ Age (yr) } \\
\hline$<20$ & 0.76 & 0.124 & 0.97 & 0.034 & 0.80 & 0.108 & 0.80 & 0.107 \\
\hline$>20$ & 0.71 & 0.000 & 0.77 & 0.000 & 0.57 & 0.002 & 0.57 & 0.002 \\
\hline \multicolumn{9}{|l|}{ Side of effusion } \\
\hline Right-sided & 0.68 & 0.004 & 0.76 & 0.019 & 0.49 & 0.053 & 0.50 & 0.049 \\
\hline Left-sided & 0.84 & 0.000 & 0.83 & 0.000 & 0.82 & 0.000 & 0.82 & 0.000 \\
\hline
\end{tabular}

$r$, Pearson correlation coefficient.

high correlation ( $r=0.75, P<0.001)$. The supine 1 (Eibenberger) and supine 2 (Balik) formulae yielded statistically significant results, but much lower correlation coefficients (Table 3).

In patients aged $<20$ years old, only the volume estimate of the erect 2 (Goecke 2 ) formula showed a statistically significant correlation ( $r=0.97, P=0.03)$. The correlation coefficients obtained from the other formulae in this category of subjects were not statistically significant.

In patients $>20$ years old, both the erect 1 (Goecke 1) and erect 2 (Goecke 2) formulae yielded statistically significant high correlations, while both supine formulae yielded statistically significant but only moderate/reasonable correlations.

The sonographic estimates of the left-sided effusions correlated excellently and significantly with the actual drainage volume for all four formulae. For right-sided effusions, the erect 1 and erect 2 formulae yielded significant and high correlations (with correlation coefficients that were much lower than those obtained for the left side), while both supine formulae yielded only moderate/reasonable and weakly significant correlations.

\section{Discussion}

The effective management of pleural effusion requires early recognition, some form of volume estimation, and identification of the underlying etiology [21]. The clinical diagnosis is often difficult when the amount of effusion is relatively small or when there is underlying lung consolidation, making it expedient to obtain radiological evidence.

These 4 formulae were evaluated because they can be performed easily and quickly, making them useful for routine clinical applications [10]. Some of the other ultrasonographic formulae published in the literature are rather cumbersome, time-consuming, and may be impracticable for day-to-day usage $[10,22]$.

A previous study [10] concluded that the erect 2 (Goecke 2) formula yielded the best estimates, with a Pearson correlation coefficient (r) of 0.87 . This finding was corroborated by our study, with results of $r=0.81$, corresponding to the most significant and strongest correlation with the actual volume drained. Erect formulae take advantage of the fact that non-loculated pleural fluid gravitates inferiorly to the lower pleural space in that position. That previous study [10] also showed that the erect 1 (Goecke 1) formula yielded a close correlation $(r=0.68)$ between the sonographic estimate and actual volume, which is quite similar to our correlation coefficient of 0.75 for the erect 1 formula. The main weakness of the erect 1 formula is that it tends to overestimate the volume of small effusions [10]. This was not a significant problem in this study, though, as the vast majority of patients had quite large pleural effusions (total mean effusion volume, 2,770 $\pm 1,841 \mathrm{~mL}$ ). This may have been responsible for our slightly higher value of $r=0.75$.

The supine formulae were developed to reflect the positiondependent distribution of fluid within the pleural cavity [9]. Free pleural fluid gravitates posteriorly in the supine position to form a sickle-shaped lamella on transverse sonograms. The widest extent/ thickness of the lamella is used for estimating the total fluid volume [9]. Eibenberger et al. [9] reported a significant and high correlation ( $r=0.80)$ between the actual volume drained and the ultrasonographic estimates they derived using the supine 1 formula. Contrary to their findings, that formula yielded $r=0.62$ in this study. Mathis [10] observed that the deviations of the estimated volume from the real volume could be considerable with this formula (supine 1). Its limitations include the fact that the same volume of pleural fluid in individuals with different-sized thoracic/pleural cavities tends to be underestimated in the larger thoracic cavities and vice versa. Similarly, diaphragmatic elevation affects the estimated effusion volume [9]. The other recognized limitation of the supine 1 formula is the effect of the lung parenchymal status on the shape of the pleural fluid. A poorly aerated/collapsed lower lobe will likely displace underlying pleural fluid, thus yielding an estimated volume 
smaller than the actual volume [9].

The supine 2 formula of Balik et al. [11] and Cerquitella et al. [12] is essentially a simplified version of the Eibenberger formula. Both groups of researchers reported the same (high) correlation coefficient $(r=0.72)$ in their studies, which is comparable to the result of $r=0.63$ that we obtained in our study.

Previous studies have reported a significant side difference (right hemithorax versus left hemithorax) in the level of correlation between sonographic estimates and actual pleural fluid volume drained [23-25]. Left-sided estimates have been observed to be slightly less closely correlated than right-sided estimates, possibly because of the presence of the heart on the left [23]. However, this was not what we observed, as estimates from the left side showed much stronger and more significant correlations than did estimates from the right side across all 4 formulae. The disparity between our results and the observations of Vignon et al. [23] and Hassan and Rizk [24] may be attributable to differences in the measurement landmarks used to derive sonographic estimates.

In conclusion, it is important to quantify pleural effusion in order to ensure prompt and effective management; in particular, when deciding whether a chest tube should be inserted, especially when the clinical presentation and clinically suspected effusion volume are discordant, and also in ascertaining the completion of pleural fluid drainage before extubation. Ultrasonography is safe, cheap, and convenient route, and is easy to use in most patients, except in very young children. It is also convenient to use in patients who are in the intensive care unit. For daily clinical applications, a simple single measurement of the volume of pleural effusion is preferable to a formula requiring multiple measurements $[22,25]$. While the two erect formulae gave quite accurate measurements, the ultrasonographically estimated volume correlated most closely with the actual volume drained when the erect 2 (Goecke 2) formula was used. It is hoped that these findings will be useful for the accurate quantification of pleural effusion in daily clinical practice.

ORCID: Bolanle Olubunmi Ibitoye: http://orcid.org/0000-0002-8799-775X; Bukunmi Michael Idowu: http://orcid.org/0000-0002-9811-5644; Babalola Ishmael Afolabi: http://orcid.org/0000-0001-6728-8799

\section{Conflict of Interest}

No potential conflict of interest relevant to this article was reported.

\section{Acknowledgments}

We thank Dr. Onigbinde and Stephen Olaoluwa for helping with the statistical analysis.

\section{References}

1. Diaz-Guzman E, Dweik RA. Diagnosis and management of pleural effusions: a practical approach. Compr Ther 2007;33:237-246.

2. Noppen M. Normal volume and cellular contents of pleural fluid. Curr Opin Pulm Med 2001;7:180-182.

3. Muller NL. Imaging of the pleura. Radiology 1993;186:297-309.

4. Na MJ. Diagnostic tools of pleural effusion. Tuberc Respir Dis (Seoul) 2014;76:199-210.

5. Light RW. Pleural diseases. 6th ed. Philadelphia, PA: Lippincott Williams \& Wilkins, 2013.

6. Guarize J, Spaggiari L. Pleural effusion. In: Schwab M, ed. Encyclopedia of cancer. Berlin: Springer-Verlag, 2011;2923-2926.

7. Tsai TH, Yang PC. Ultrasound in the diagnosis and management of pleural disease. Curr Opin Pulm Med 2003;9:282-290.

8. Ferreira AC, Filho FM, Braga T, Fanstone GD, Chodraui IC, Onari N. The role of ultrasound in the assessment of pleural effusion. Radiol Bras 2006;39:145-150.

9. Eibenberger KL, Dock WI, Ammann ME, Dorffner R, Hormann MF, Grabenwoger F. Quantification of pleural effusions: sonography versus radiography. Radiology 1994;191:681-684.

10. Mathis G. Pleura. In: Mathis G, ed. Chest sonography. 3rd ed. Heidelberg: Springer-Verlag, 2011;30-32.

11. Balik M, Plasil P, Waldauf $P$, Pazout J, Fric M, Otahal $M$, et al. Ultrasound estimation of volume of pleural fluid in mechanically ventilated patients. Intensive Care Med 2006;32:318.

12. Cerquitella M, Saccomandi P, Schena E, Silvestri S, Scarlata S, Giua R. Ultrasound estimation of pleural effusion in geriatric patients. In: IEEE International Symposium on Medical Measurements and Applications (MeMeA); 2016 May 15-18; Benevento, Italy; INSPEC accession No. 16211740.

13. Azoulay E. Pleural effusions in the intensive care unit. Curr Opin Pulm Med 2003;9:291-297.

14. Colins JD, Burwell D, Furmanski S, Lorber P, Steckel RJ. Minimal detectable pleural effusions: a roentgen pathology model. Radiology 1972;105:51-53.

15. Qureshi NR, Gleeson FV. Imaging of pleural disease. Clin Chest Med 2006;27:193-213.

16. Kocijancic I. Imaging of small amounts of pleural fluid. Part one: small pleural effusions. Radiol Oncol 2005;39:237-242.

17. Giron-Ramos GV. A comparative study on the radiographic and sonographic presentation of pleural effusion in children: to establish the value of chest radiograph with regards to the recognition and quantification of pleural effusion and to establish the minimum amount. Chest 2008;134(4 Suppl 2):140P.

18. Joshua A, Shetty L, Pare V. Variations in dimensions and shape of thoracic cage with aging: an anatomical review. Anat J Afr 2014;3:346-355.

19. Muller NL, Bryan AC. Chest wall mechanics and respiratory muscles 
in infants. Pediatr Clin North Am 1979;26:503-516.

20. Harris M, Taylor G. Medical statistics made easy. London: Martin Dunitz, 2003;48-52.

21. Oguntoyinbo AE, Adeoye PO, Rahman GA, Abdulkadir AY. Radiological and clinical pattern of pleural effusion in llorin. West Afr J Radiol 2008;15:1-5.

22. Remerand F, Dellamonica J, Mao Z, Ferrari F, Bouhemad B, Jianxin $Y$, et al. Multiplane ultrasound approach to quantify pleural effusion at the bedside. Intensive Care Med 2010;36:656-664.
23. Vignon P, Chastagner C, Berkane V, Chardac E, Francois B, Normand $S$, et al. Quantitative assessment of pleural effusion in critically ill patients by means of ultrasonography. Crit Care Med 2005;33:1757-1763.

24. Hassan M, Rizk R. Pleural effusion volume estimation by thoracic ultrasound. Chest 2016;149(4 Suppl):A439.

25. Ashton-Cleary DT. Is thoracic ultrasound a viable alternative to conventional imaging in the critical care setting? $\mathrm{Br} J$ Anaesth 2013;111:152-160. 